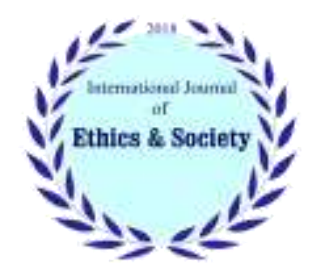

International Journal of Ethics \& Society (IJES)

Journal homepage: $\underline{\text { www.ijethics.com }}$

Vol. 2, No. 4 (2021)

(Original article)

\title{
Effectiveness of Kohlberg's Dilemmas \& Inducing Positive Emotion in Emotional Expectation \& Moral Decision Making
}

\section{Touran Alizadeh*, Maryam Elahizadeh}

Farbangian University, Kosar Pardis, Yasuj, Iran.

\section{Abstract}

Background: The aim of this study was to investigate the effectiveness of Kohlberg's dilemmas teaching methods and induction of positive emotion on emotional expectations and moral decision making of adolescent girls.

Method: The research method was quasi-experimental (pre-test and post-test) with a control group. The statistical population was all female students in the first grade of high school (second year) in Yasuj province who were selected by multi-stage cluster sampling and randomly assigned to three groups $(n=30)$. The experimental and control groups completed the scenarios of emotional expectations and daily ethical decision-making tasks as pre-test and post-test. Multivariate analysis of covariance was used to analyze the data.

Results: The data showed that Kohlberg's hypothetical dilemmas methods and induction of positive emotion in the post-test stage were effective in improving emotional expectations and moral decision making $(\mathrm{p}<0.001)$. The results of post hoc test showed that there was a significant difference between the intervention groups (Kohlberg's hypothetical dilemmas and induction of positive emotion) with the control group $(p=0.001)$.

Conclusion: Kohlberg's hypothetical dilemmas teaching method and induction of positive emotion are effective on emotional expectations and moral decision making of first grade high school female students.

Keywords: Kohlberg's dilemmas, Positive emotion induction, Emotional expectations, Moral decision making

\section{Introduction}

Moral is defined as the good and bad evaluation of a person's actions or character, which is constructed by justifying a set of virtues and which a culture or subculture requires (1). Moral decision-making describes moral situations and conflicts in people's daily lives and examines whether individuals pay attention to moral imperatives. Moral decision-making is the decision of individuals to help someone or not. Today, children and adolescents face more challenges than in the past, and answering these

*Corresponding Author: Email: toran.alizadeh@yahoo.com

Received: 18 Dec 2020

Accepted: 20 Jan 2021

10

Available at: www.ijethics.com 
challenges requires the skills of review, comparison, and decision-making (2). Kohlberg's dilemmas are hypothetical and abstract dilemmas. These dilemmas are taken from stories in which the criteria are not personal or are considered impersonal and hypothetical.

In summary, research has shown the effectiveness of moral dilemmas and debates in increasing the power of moral decision-making. The more social provocations derived from Kohlberg's dilemmas, the faster moral growth takes place. moral issues are one of the most complex and controversial issues, and a study examining the role of education in the development of moral behavior based on Kohlberg theory found that people who were trained in moral behavior had better judgment and decision-making ability than the control group. (3-5).

Contradictory ideas about the role of emotion and cognition in moral judgment have led to much research. In these studies, most of which use emotional induction, emotion is defined as: The rapid response evoked when a person is exposed to a meaningful stimulus and calls for an adaptive response (6).

A study of the role of cognition and emotion in moral judgment concluded that: Conscientious judgments (not approving the killing of one person for several) are formed with automatic emotional responses, while utilitarian judgments (approving the killing of one to save the lives of several) controlled cognitive processes arise $(7,8)$.

Positive emotions increase the range of our behavior and thoughts, while negative emotions reduce this range. Positive emotions create patterns of thought that are flexible, pervasive, and receptive, and lead to more valuable actions. In summary, the results of many studies have shown the effectiveness of positive emotion in solving puzzles and improving moral decision-making. In a study of the divergent effects of positive emotions, it was found that positive emotions facilitate better and more correct decision making (7-10).

The study found that although older children at all ages attributed negative emotions to violators of moral principles, most young children attributed positive emotions such as (happiness) to offenders.
The study reported positive emotion for the happy abuser $(11,10)$.

However, a person who waits for his or her feelings and emotions - a severely negative assessment when engaging in an immoral act - is more likely to find moral behavior more important than one who experiences personal satisfaction in committing the same immoral act. Emotions and feelings affect not only behavior but also moral decision making (10). Lack of fixed and universal foundations for moral education is one of the main problems in moral education. In our country, in the field of moral education, only the teaching of moral values or direct education is emphasized (12), therefore, the question arises whether other methods such as: cognitive education and induction of emotions can contribute to the moral development of students? In no other period are moral values and standards raised for human beings as much as in adolescence. Adolescents' increasing cognitive abilities draw their attention to moral issues and values. At the same time, what society wants from adolescents is changing rapidly, and this requires constantly reevaluating and deciding on moral values and beliefs. Given the above, if the factors influencing moral decision-making and emotional expectations for acting on the dimensions of moral judgment and behavior (social and anti-social) can be identified, it may be possible to intervene as predictors and improve intervention and education. Moral decisionmaking and adolescents' emotional expectations took action, thereby increasing the number of ethical students in society.

\section{Material and Methods}

The method used in this research is a quasi-experimental "pre-test and post-test" with a control group. The statistical population of this study was all female students in the first grade of high school (second year) aged 15-16 years in Yasuj province, which at the time of the study, their number was about 1960 people. The sampling method in this study was multi-stage cluster sampling. After sampling, 3 high schools were randomly selected and 
from each high school, a first grade class was randomly selected as a cluster. Individuals in a group (a class of 30) were randomly trained in Kohlberg's dilemmas in 8 sessions of 70 minutes. The other group was also under positive emotion induction. The control group did not receive any intervention. The sample group completed the following tools to collect information before and after the intervention.

Emotional expectations scenarios: The set of emotional expectations scenarios includes 16 stories in two forms. Execute emotional expectation scenarios were performed in groups. First translated after receiving. Scenarios with four consequences and each outcome in two stories; happy moralists, unhappy moralists, happy abusers, and unhappy abusers are classified. Participants imagine themselves in the role of the protagonist or role model and, taking into account the emotions of the role model, express what decision the protagonist makes. In this study, the total score of people in emotional expectations is calculated. The minimum score in these scenarios is 8 and the maximum is 56 . The closer a person's score is to 8 , the more it reflects ethical expectations (10).

The factor load matrix showed that all the extracted factor loads are above 0.46 and the distribution of substances in the subscales corresponds to the main instrument. In the study (15), Cronbach's alpha is 0.77 for ethical scenarios, while 0.75 is reported for aggression scenarios. In the present study, the Cronbach's alpha for the questionnaire was obtained by the method of halving 0.74 , which is acceptable.

Daily moral decision making test: Decision dilemmas were used. A set of 20 dilemmas that describe situations or moral conflicts in which moral obligation is taken into account or vice versa. Half of these 20 dilemmas create high excitement and the other half create low excitement. Each of these 20 dilemmas alternately presents altruistic or selfish decisions (14). After answering yes and no to each puzzle, the subject imagines himself in the situation at the time, and the excitement created scores his moral decision-making on a four-point Likert scale (by no means 1, somewhat 2, more 3, and too much 4). The dilemma is: You go to a stationery store that has two booklets of the same color and shape that are different in price. Both booklets get your attention, you pick them both up, the seller doesn't notice. Do you pay for a cheaper booklet?

According to the data, the confirmation model had an acceptable fit. The factor load matrix showed that all extracted factor loads are above 0.40 and the distribution of substances in the subscales is consistent with the main tool. In a study (10) Cronbach's alpha coefficient for subscales of selfcentered and altruistic responses was 0.88 and 0.81 and for the whole test was 0.89. Also in another study (20) instrument reliability, Cronbach's alpha was reported using the retest method with a time interval of 0.83. In this study, Cronbach's alpha of the whole scale was 0.77 and for subscales of selfcentered and altruistic responses was 0.74 and 0.78 . Research process: One experimental group was trained separately in 8 sessions of 70 minutes, using Kohlberg's hypothetical dilemmas, and the other group was induced with positive emotion induction.

The steps of these methods are: 1- Selecting dilemma stories, 2- Preparing for discussion and explaining the rules of discussion, 3- After presenting puzzling stories, one of the students repeats the story and asks questions about the story, 4- Choosing possible solutions 5 - Discuss in small groups about the solution, 6 - Discuss in the whole class and express the pros and cons and examine the reasons for them and 7 - Concluding the discussion, voting on the best solution and writing a suitable ending for the puzzle story.

Positive emotion induction method: Differences in increasing or decreasing the scores of individuals before and after viewing the images, the individual score of emotion induction is considered. In this method, students were presented with visual emotional stimuli, i.e. positive images. In the present study, first 80 images (40 neutral images and 40 happy images) were selected according to the global norm and at the same time in accordance with Iranian culture. Then, among them, 22 images with positive emotional charge and 14 images with neutral emotional charge were used. To ensure the validity of emotional stimuli, in a pilot study, the effect 
of selected images on 30 students (excluding students in the sample group) was examined. Each image appeared on the screen for about 10 seconds, and the order in which the images were presented was the same for everyone. After selecting the sample people, according to a schedule, the subjects came to the computer site. After the subjects arrived and completed their personal details, the subjects sat in a chair in front of a computer screen that displayed the images. For each subject, first neutral mood induction (presentation of images without emotion) was performed in four minutes, then presentation of happy mood images was performed for four minutes (9).

\section{Results}

Multiple covariance analysis was used to analyze the data. Before analyzing the results in relation to the research hypotheses, the test assumptions were confirmed. As can be seen in table (1), the findings indicate that the value of multivariate $\mathrm{F}$ (6.65) is significant at the level $(\mathrm{p}<0.000)$. Therefore, it can be said that there is a significant difference between the experimental and control groups in at least one of the dependent variables (style of emotional expectations and moral decision making).

To find out the difference, multivariate analysis of covariance was used to test the hypotheses.

Table 1: Multivariate analysis of covariance to examine the effect of group variable on emotional expectations and moral decision making

\begin{tabular}{|c|c|c|c|c|c|c|}
\hline Type of test & & Value & F & Hypothesis df. & Error df. & Sig. \\
\hline \multirow{3}{*}{$\begin{array}{c}\text { Groups in post- } \\
\text { test }\end{array}$} & Pillai's trace & 0.476 & 6.65 & 12 & 423 & 0.000 \\
\cline { 2 - 7 } & Wilks' Lambda & 0.569 & 7.28 & 12 & 368 & 0.000 \\
\cline { 2 - 7 } & Hotelling's trace & 0.679 & 7.79 & 12 & 413 & 0.000 \\
\cline { 2 - 7 } & Roy's largest root & 0.534 & 18.81 & 4 & 141 & 0.000 \\
\hline
\end{tabular}

Table 2: Multivariate analysis of covariance of post-test scores with pre-test control of variables (emotional expectations and moral decision making) in the control and experimental group

\begin{tabular}{|c|c|c|c|c|c|}
\hline Type of test & Value & F & PES & Sig. \\
\hline \multirow{3}{*}{$\begin{array}{c}\text { Groups in post- } \\
\text { test }\end{array}$} & Pillai's trace & 0.59 & 40.55 & 0.59 & 0.000 \\
\cline { 2 - 6 } & Wilks' Lambda & 0.40 & 40.55 & 0.59 & 0.000 \\
\cline { 2 - 6 } & Hotelling's trace & 1.47 & 40.55 & 0.59 & 0.000 \\
\cline { 2 - 6 } & Roy's largest root & 1.47 & 40.55 & 0.59 & 0.000 \\
\hline
\end{tabular}

According to the contents of table 2, there is a significant difference between the experimental and control groups in at least one of the dependent variables (emotional expectation style and moral decision making). To investigate the point of difference, one-way covariances were analyzed in MANCOVA text on dependent variables.

The results in table 3 show that one-way covariance analysis is significant in the variables of emotional expectations $(\mathrm{F}=16.58$ and $\mathrm{p}=/$ 0001 $)$ and moral decision making $(\mathrm{F}=69.08$ and $\mathrm{p}=0.0001)$.
Therefore, the research hypothesis based on the effectiveness of Kohlberg's hypothetical dilemmas on emotional expectations and moral decisionmaking of adolescent girls is confirmed.

According to the contents of table 4, there is a significant difference between the experimental and control groups in at least one of the dependent variables (emotional expectation style and moral decision making). To investigate the point of difference, one-way covariance were analyzed in MANCOVA text on dependent variables. 
Table 3: One-way analysis of covariance to examine the effect of Kohlberg's hypothetical dilemma training on emotional expectations and moral decision making

\begin{tabular}{|c|c|c|c|c|c|c|c|}
\hline Effect & Dependent variable & SS & df & MS & $\mathbf{F}$ & $\mathbf{P}$ & Effect size \\
\hline \multirow{2}{*}{ Groups } & Emotional expectations & 307.84 & 1 & 307.84 & 16.58 & 0.001 & 0.22 \\
\hline & Moral decision-making & 1365.05 & 1 & 1365.05 & 69.08 & 0.001 & 0.55 \\
\hline
\end{tabular}

Table 4: Multivariate analysis of covariance of post-test scores with control of pre-test of variables (emotional expectations and moral decision making) in the experimental and control group

\begin{tabular}{|c|c|c|c|c|c|}
\hline Type of test & & Value & F & PES & Sig. \\
\hline \multirow{3}{*}{$\begin{array}{c}\text { Groups in post- } \\
\text { test }\end{array}$} & Pillai's trace & 0.43 & 21.24 & 0.43 & 0.001 \\
\cline { 2 - 6 } & Wilks' Lambda & 0.56 & 21.24 & 0.43 & 0.001 \\
\cline { 2 - 6 } & Hotelling's trace & 0.77 & 21.24 & 0.43 & 0.001 \\
\cline { 2 - 6 } & Roy's largest root & 0.77 & 21.24 & 0.43 & 0.001 \\
\hline
\end{tabular}

Table 5: One-way analysis of covariance to investigate the effect of positive emotion induction on emotional expectations and moral decision making

\begin{tabular}{|c|c|c|c|c|c|c|c|}
\hline Effect & Dependent variable & SS & df & MS & $\mathbf{F}$ & $\mathbf{P}$ & Effect size \\
\hline \multirow{2}{*}{ Groups } & Emotional expectations & 768.64 & 1 & 768.64 & 27.23 & 0.001 & 0.33 \\
\hline & Moral decision-making & 96.08 & 1 & 96.08 & 8.85 & 0.001 & 0.13 \\
\hline
\end{tabular}

The results in table 5 show that the analysis of oneway covariances is significant in the variables of emotional expectations $(\mathrm{F}=16.58$ and $\mathrm{p}=/ 0001)$ and moral decision making $(\mathrm{F}=69.08$ and $\mathrm{p}=$ 0.0001). Therefore, the hypothesis of research on the effectiveness of positive emotion induction on emotional expectations and moral decision-making of adolescent girls is confirmed.

\section{Discussion}

Based on the research findings, it was found that the variable scores of ethical decision making and emotional expectations have improved compared to the control group; however, the extent of these changes was not the same in the intervention groups.

The research findings on the effectiveness of Kohlberg's hypothetical dilemmas training are consistent with the findings of others' research that group rhetoric training on moral dilemmas promotes moral judgment. In explaining this finding, it can be said that when it comes to ethical issues. We argue that we are not like one who considers the evidence and arguments to seek the truth, but I am like a lawyer who tries to find convincing evidence $(3,5,15,16)$.

In addition, according to the theoretical framework of the developmental-cognitive approach, the reason for the effectiveness of education and participation in ethical dilemmas on students' moral decision-making is the emphasis on the principle of cognitive conflict and role-playing, which are processes affecting cognitive and moral development.

On the other hand, according to researchers, learning ethics requires using higher levels of moral and cognitive reasoning, paying attention to the views of others and considering their theories, being open to opposing views, and empathizing more with the role of models in moral scenarios. The method of moral dilemmas, the above factors are more visible than other methods $(12,17)$.

In addition, because Kohlberg's dilemmas are hypothetical or semi-real, people are free to consider the moral aspects of the issue without comment, and are openly encouraged to discuss verbal debates and reasoning to judge and decide on moral riddles. They listen to and criticize the opinion of others, which increases people's decision-making in moral issues (16). 
As the researchers suggested, purposeful educational interventions through group discussion encourage and motivate ethical decision-making in individuals. Group discussions about moral riddles, especially relationships with peers, can have a major impact on improving moral reasoning (3). The findings of this study also showed that the induction of positive emotion was effective on moral decision making. This finding was consistent with the findings of many studies $(2,7,9$, 18).

Explaining this finding, we can say that positive emotions lead moral thoughts positively. According to link network theory, emotional states play a key role in information processing. These theories suggest that each emotion is linked to its own cognitive content. For example, positive emotion-related cognitions are associated with the evaluation of achievement of benefits (19)

The pervasive effect of emotion on thinking and judgment was examined. The results show that positive emotional information increases cognitive responses and negative emotional information decreases cognitive responses. As a result, positive emotion facilitates the process of moral thinking. In addition, positive emotions increase the range of behavior and thoughts and negative emotions decrease this range. A study was conducted on the divergent effects of different positive emotions on moral judgment. The results showed that cheerfulness increased facilitation for morality, while elevation had the opposite effect $(13,9)$.

Negative emotion seems to draw our attention to the moral characteristics of the situation. The results of a study showed that people who participated in moral puzzles had worse moral judgments and decisions than the control group after sitting at a dirty table or inhaling a foul odor. Responding to moral dilemmas causes high activity in areas of the brain associated with emotional processing, but this increase in activity is not seen in immoral responses. In addition, positive emotions create patterns of thought that are noteworthy, unusual, flexible, creative, and receptive, and these positive emotions create more creative and valuable actions that enhance moral decision-making (7).
Given this, it can be said that: positive emotions improve moral decision making.

Another finding of the study showed that both methods (teaching Kohlberg's dilemmas and inducing positive emotion) are effective in improving emotional expectations. A review of the research literature shows that in general, no research has been done on the effect of education on people's moral and emotional expectations, but the results of this study are in line with the results of research that believe that emotional responses such as empathy with levels of moral reasoning And direct help to peers $(13,19,20)$.

Explaining this finding, it can be inferred that: In general, morally charged situations have an emotional basis and can bias moral motivators to reduce undesirable emotional responses. There is evidence that emotional responses are not merely the result of social and moral evaluation but also shape these evaluations. Moral emotions generally arise from the interaction between values, norms, and contextual components of social situations and are evoked in response to violence or social expectations (16).

In addition, one of the developmental abilities associated with the process of moral development is the capacity to consider the views of others. This is especially important because being social requires interacting with others and understanding their point of view. Based on the evidence presented, some researchers claim that the opportunities that society provides for children and adolescents to play a pivotal role and participate in group discussions, improve their understanding of others' perspectives, reduce their sense of self-centeredness, and promote thinking. Morality creates them. Some theorists have argued that the differences between members of different societies and cultures in reaching particular stages of moral development may be explained by their differences in the amount of opportunities available for comment $(20,21)$.

The pattern of moral emotional expectations explains how individuals attempt to exhibit individual behaviors based on internal or external factors for themselves and others. Moral emotion attrib- 
utes to actual behavior (e.g., guilt) are felt after disobeying a moral norm, and emotions trigger certain actions (e.g., empathy leads to helping others. As a result, cognitive education changes the abusive style. Emotional expectations shift to an ethical style (10.11.13).

In fact, research has shown that people's perceptions of the severity of moral violations stem from their emotional response to them. Therefore, it is not yet clear whether emotional expectations influence moral decisions or are the result of these decisions.

Although this study has tried to reduce the annoying variables and possible biases by randomly assigning groups to experiments and controls, but because the classes were already formed, it was not possible to randomly assign individual students to the experimental and control groups. Differences in the degree to which the classes cooperated with individuals were also other cases in that some classes did not cooperate with us enough, and the researcher tried to control this limitation as much as possible with sufficient explanation. Also, the limited statistical population to female high school students, which limits the possibility of generalizing the results of this study to other groups, is also one of the limitations of the research.

This study was performed only on female high school students in the first grade of high school. Therefore, it is suggested that this research be conducted among male students, as well as other age and educational levels, so that the results and the effectiveness of these methods can be discussed more accurately and confidently. It is recommended that in future research, a more comprehensive study of possible factors and methods affecting emotional expectations and moral decision-making be done and based on that, a model for the development of moral decision-making and emotional expectations of individuals be designed. It is recommended that the effectiveness of cognitive methods and the induction of positive emotions on moral behaviors be done. Also, study the effectiveness of hateful, frightening and sad emotions on moral decision making and emotional expectations is suggested. Another recommendation is to teach students about conflicting values and norms in schools. The results showed that encouraging participation and verbal and argumentative discussion to judge moral riddles and answer students' ambiguities leads to improved moral decision-making and their emotional expectations.

\section{Conclusion}

Findings showed that the use of educational method (Kohlberg's hypothetical dilemmas) and intervention method (induction of positive emotions) was effective on students' moral decisions and emotional expectations and improved their grades. In addition, Kohlberg's hypothetical dilemmas teaching method was more effective. Research by cognitive psychologists has shown that students' attainment of higher moral levels depends not only on their cognitive development, but also on being in natural situations, solving social and moral problems, and actively thinking about them, which internalizes values and moral growth. Accordingly, the moral thinking of children and students can be influenced in three ways: 1- Facing students with higher level arguments

2- Facing students with situations that confront the mental structure with problems and contradictions.

3- Creating an atmosphere of confrontation so that conflicting moral opinions can be compared in a free style.

According to another study, induction of positive emotions also improved students' moral decisionmaking and emotional expectations. Different systems in the brain control moral decision-making, one of which is responsible for the emotional responses involved (2). Based on the findings, it can also be stated that personal stories and decisions that have an emotional gender in general are more affected by environmental factors, especially emotions, than decisions that have a sexual nature.

\section{Ethical Consideration}

In this study, the principles and rules of scientific ethics such as fidelity, confidentiality, conscious satisfaction and honesty have been considered. 


\section{Acknowledgement}

We sincerely thank the director of education of Yasuj province and all the students who have helped the researchers in implementing this gift.

\section{References}

1. Haidt J (2008). The new synthesis in moral psychology. Science, 316: 998-1002.

2. Greene JD (2015). The cognitive neuroscience of moral judgment and decision making. In: J. Decay \& T. Wheatley (Eds.). The moral brain: A multidisciplinary perspective. Boston Review, USA . Pp. 197-220

3. Cummings R, Maddux C.D, Cladianos C, Richmond A (2010). Moral reasoning of education students: the effects of direct instruction in moral development theory and participation in moral dilemma discussion. Teacher College Record, 112: 621-644.

4. Latif D, Dunne B (2008). The relationship between ethical dilemma discussion and moral development. American Journal Pharmaceutical Papers in Education, 23:37-52.

5. Motlagh A (1390). Investigating the effect of debate in morally enigmatic stories on the development of moral judgment of fifth grade students. [M.A Thesis]. Allameh Tabatabai University, Tehran/Iran. (In Persian).

6. Huebner B, Dwyer S, Hauser M (2010). The role of emotion in moral. Journal of Psychology, 734: 1-16.

7. Huebner B (2015). Do emotions play a constitutive role in moral cognition? International Review of Philosophy, 1(2).

8. Strohminger N, Lewis RL, Meyer DE (2011). Divergent effects of different positive emotions on moral judgment. Journal of Cognition, 119: 295-300.

9. Ziaei M, Khodapnahi MK, Heidari MV (2009). Investigating the effect of emotional induction on the speed of personal and impersonal moral judgments. Journal of Behavioral Sciences, 7:155-167. (In Persian).

10. Krettenauer T, Jia F, Mosleh M (2011). The role of emotion expectancies adolescent's moral decision marking. Journal of Experimental cbild psychology, 108: 359-370.
11. Paul LJ, KrettenauerT. (2020). Is the true self truly moral? Identity intuitions across domains of sociomoral reasoning and age. Journal of Experimental Child Psychology, 192.

12. Sajjadi SM (2007). Explanation and critique of the principles of postmodern moral education. Educational Research and Revien, 12: 130-143. (In Persian).

13. Malti T, Keller M (2010). The development of moral emotions in a cultural context. In: Arsenio WF, Lemerise EA. (Eds.). Emotions, aggression, and morality in children: Bridging development and psychopathology. Publication of American Psychological Association, Washington/USA.

14. Starcke K, Polzer C, Wolf T, Brand M (2011). Does stress alter everyday moral decision making? Journal of Psychoneuroses' Endocrinology, 36: 201-219.

15. Strohminger N, Lewis RL, Meyer DE. (2011). Divergent effects of different positive emotions on moral judgment. Journal of Cognition, 119: 295-300.

16. Chang FY. (1994). School teachers moral reasoning. Psychology \& Applied Ethics, 54: 71-83.

17. Karimi F, Bagheri K, Sadeghzadeh Ghamsari A (2014). The effect of three methods of group discussion on moral dilemmas, small group discussion in a participatory way and lecturing on the development of moral judgment of female high school students. Journal of New Psychological Researh, 33: 262-218. (In Persian).

18. Johnston DW. (2009). Moral emotion expectancies and moral behavior in adolescence. [BA thesis]. University of Western Ontario, Canada.

19. Fakhari A, Rostami MA, Nazari A, Growsi Farshi MT (2011). The effect of induced mood on the asymmetry of the frontal lobe of the brain in individuals with behavioral activating and inhibiting systems. Behavioral Science Research, 10: 12-29. (In Persian)

20. Kreb D, Denton K. (2017). Rational and emotional sources of moral decision-making: an evolutionary-developmental account. Evolutionary Psychological Science, 3(1).

21. Thowfeek R, Bulman RJ, Tavemini J. (2011). Moral judgments and the role of social harm: Differences in automatic versus controlled processing. Joumal of Experimental Social Psychology, 47: 1-16. 